\title{
Las nanas: ¿una canción femenina?
}

En gran parte de los cancioneros que editan lírica tradicional, los textos se presentan ordenados de acuerdo a la función que cumplen. Generalmente se halla un apartado dedicado a las rimas y juegos infantiles donde se encuentran las canciones de cuna. Estas últimas, si bien están dentro del ámbito infantil y los niños son sus destinatarios, difieren de las primeras en que los encargados de su transmisión son los adultos. Nada más basta recordar la inmediata asociación de las nanas con la imagen de la madre susurrando suaves sonidos al niño en sus brazos.

El papel tradicional de la mujer como encargada del cuidado del niño quizás ha sido una de las principales causas de que las canciones de cuna sean identificadas como canción de voz femenina, dejando a un lado el estudio de los textos mismos. En otras palabras, la mayoría de los estudiosos han puesto el énfasis en la enunciación y no en el enunciado. Este último aspecto es el que me propongo estudiar aquí.

Este artículo se basa en el análisis de 67 cantares que provienen de diversas regiones de España y Portugal. La selección de textos respondió a un criterio de difusión geográfica de acuerdo con el cual el repertorio estudiado aspira a ser una breve muestra representativa ${ }^{1}$.

\section{EL NOMBRE DE LA NANA}

El arrullar al niño es una acción universal que goza de una variada gama de interpretaciones según la lengua en que se realice ${ }^{2}$. Algunos

1 En este artículo prefiero usar el término cantar o cantarcillo para designar a las coplas, y canción para la serie de coplas.

2 Véanse para el origen del nombre y tipología del género los interesantes trabajos de Giuseppe PITRÉ, Canti popolari siciliani (Biblioteca delle Tradizioni Popolari Siciliani, I) (Palermo: Pedone Lauriel, 1871), pp. 1-2; Francisco Rodrf́guez Marin, Cantos populares españoles (Buenos Aires: Bajel, 1948), pp. 514-15 labrev. Rodríguez Marín, Cantos; José LeITE DE VAsConcellos, .Canções do berço- en sus Oprisculos, VII, Etnología, II (Lisboa: Imprensa Nacional, 1938), pp. 780-927 [abrev. Leite de Vasconcellos, -Canções»]; José Pérez VIDAL, Folclore infantil canario (Madrid: Cabildo 
testimonios permiten suponer el uso de la repetición de voces en los cantares de cuna desde tiempos antiguos. Quizá por ello, cuando se habla de nanas, parece imposible dejar de citar la curiosa y acertada definición dada por Rodrigo Caro en su obra Dias geniales o lúdricos; en ella explica que «las reverendas madres de todos los cantares y los cantares de todas las madres [...] son nina, nina y lala, lala. El eminente humanista se apoya en citas de diferentes autores latinos para explicar la etimología de las voces. Confirma su opinión con la cita de los Ausoniarum lectionum libri duo de Scaligero quien explica que "qua pueris inducunt somnos, subinde hoc repetendo 'Lalla, Lalla'" ${ }^{3}$.

En el siglo XVII, Covarrubias, en el Tesoro de la lengua Castellana, define el verbo arrullar como la acción de *adormecer el niño con cantarle algún sonecito, repitiendo esta palabra: ro, ro; y él mesmo suele con un quexidito en esta forma adormecerse, que llaman arrullarse" ${ }^{4}$. En el siglo XVIII hallamos en el Diccionario de Autoridades las expresiones 'nina nana' definidas, de modo muy similar a 'ro-ro', como "voces sin significación alguna, de que se vale el que canta para seguir algún son, sin pronunciar palabras" 5 .

$Y$, finalmente, según Corominas, deriva el vocablo nana de las palabras Nonnus, Nonna («anciano, cuidador de niños", "abuelo, a"). El autor continúa:

finalmente, no olvidemos el castellano nana, que ya aparece una vez en Berceo, en el sentido de 'esposa' (seguramente 'esposa de edad') [...]; de ahí el antiguo nana ('mujer casada, 'madre') que la Academia da como antiguo ya en 1817, y que según ediciones posteriores significa familiarmente 'abuela' (bien conocido, al menos en la expresión el año de la nana o de la nanita), en algunas partes 'canto con que se arrulla a los niños', y en México 'niñera' y 'nodriza' 6 .

Insular de la Gran Canaria, 1986), pp. 29-77 [abrev. Vidal, Folclore]. Además, véanse acerca de la antigüedad del género los estudios de Walter FARBER, "Magic at the Cradle: Babylonian and Asyrian Lullabies", Anthropos, 85 (1990), pp. 139-48 [abrev. Farber, "Magic.]; St. H. STEPHAN, .Palestinian Nursery Rhymes and Songs*, Journal of the Palestine Society, 12 (1932), pp. 1-24.

3 Rodrigo Caro, Días geniales o lúdricos (ed. Jean-Pierre Etienvre, Clásicos Castellanos, 213) (Madrid: Espasa-Calpe, 1978), II, pp. 240 y 247.

4 Sebastián de Covarrubias, Tesoro de la lengua castellana o española (ed. M. de Riquer) (Barcelona: Horta, 1943).

5 Diccionario de Autoridades (Madrid: Gredos, 1963) (ed. facsímil, 3 vols.).

- Joan COROMINAS, Diccionario crítico etimológico castellano e bispánico (Berna: Francke, 1954), s. v. Nonnus nonna. En Portugal, aparecen las primeras referencias escritas en el primer cuarto del siglo XVI (Leite de Vasconcellos, "Cançōes", pp. 793-96). En Marruecos, particularmente en la región de Fez -explica James T. MONROE [*Estu- 
En Italia, la repetición de sonidos más difundida que ha pasado a designar la canción de cuna es la de "ninna-nanna. En el diccionario etimológico italiano de Battestti-Alessio las voces Ninna-nanna, fechadas en el siglo XIX, se definen como la "Cantinela per addormentare i bimbi" y la voz ninnare, que proviene del siglo xIII, se define como wil cullare il bambino per conciliargli il sonno. Parole di origine bambinesca" ?

Por otra parte, en el diccionario de etimologías inglesas de Eric Partridge aparece la voz lullen ('to hume a tune to') derivada de la expresión latina lallarey de ahí la palabra lullaby para definir la canción de cuna ${ }^{8}$.

De acuerdo con los diccionarios consultados, las voces nina-nana, lala y ro, ro designaban un sonido sin significación alguna. Más tarde estas voces pasan a designar la canción de cuna en sí, y, en casos como nana, el significado se expande hasta designar a la nodriza. El uso de estas expresiones parece depender más de una preferencia lingüística regional que de una preferencia estética ${ }^{9}$.

dios sobre las jaryas: las jaryas y la poesía amorosa popular norafricana", $N R F H, 25$ (1976), 1-16, p. 9]- aparece en el estribillo de la poesía amorosa en voz femenina, género conocido con el nombre de acrubi, la repetición de sonidos "nana-nana" que pueden designar a la madre, a la abuela o a la nodriza. Esta voz también aparece en las canciones de cuna en todo el norte de África, por ejemplo: „nánni nánni ž-ak en nôm / omm-ak gámra u bũ-k nžōm. "Nánni nánni, te vino el sueño; / tu madre es una luna y tu padre, las estrellas' y - Nenna nenna nenna ho / nenna nenna nam nenna 'Nenna, nenna, nenna oh, / nenna, nenna, duerme, nenna'». Además, añade Monroe, que al parecer, hay en la tradición popular árabe un cruce entre la canción de cuna y la canción erótica con ecos que se remontan a la tradición sumeria en la que Inanna era tanto la amada como la madre de Dumuzi. Por otra parte - de acuerdo con Farber- en canciones de cuna del periodo de la Vieja Babilonia donde aparece el motivo del llanto del niño que perturba la paz del hogar, aparecen nombrados los dioses Ea, Ishtar y Antu, como se ve en el siguiente texto: "Baby who made his father nervous, made tears fill the eyes of his mother, whose crying, the din of whose wheeping caused the kusariku get frightened, caused Ea to awake-yes, Ea woke up, cannot fall asleep again, and Ishtar also cannot find sleep anymore!* (*Magic", p. 145). Cabe entonces la pregunta de si el vocablo $\mathrm{Ea}$, que aparece en nuestras canciones de cuna, tiene origen tan remoto. Otra interesante coincidencia sucede en la lengua swahili, donde para expresar -yo duermon se dice 'ninalala' que viene del verbo dormir 'kulala'.

7 C. BATtisti y G. Alessio, Dizionario etimologico italiano (Firenze: G. Barbera, 1954), IV.

8 Eric PARTRIDGE, Origins: A Short Etymological Dictionary of Modern English (London: Routledge, 1959).

9 Vet VIDAL, Folclore, pp. 33-38. 


\section{LAS NANAS ANTIGUAS}

De acuerdo con las citas anteriores, existe desde los siglos XVI y XVII un reconocimiento de la canción de cuna como un género, en Italia y la Península Ibérica. Por su parte, en Inglaterra, Iona y Peter Opie afirman que "the lullaby has been recognised as a literary form for six centuries, ever since, in the reign of Edward II, an Anglo-Irish priest wrote,

Lollai, lollai, litl child,
Why wepistou so sore?
Nedis mostou wepe,
Hit was iyarkid the yore.

$Y$ añaden, "There was necessarily an established folk tradition in being when this happened, and undoubtedly long before. As John de Trevisa put it in 1398, 'Nouryces use lullynges and other songs to pleyse the wyttes of the chylde " ${ }^{10}$. Margit Frenk llega a una conclusión similar cuando explica que la "notable fidelidad con la que muchas de ellas [rimas infantiles] han sobrevivido en el folklore [...] nos hace pensar que serían muy antiguas cuando se pusieron por escrito" ${ }^{1}$.

A pesar de que la antigüedad de las nanas o arrorrós sea reconocida, el problema con el cual se enfrenta el estudioso es el de la dificultad de hallar suficientes testimonios escritos anteriores al siglo XIX. Sin embargo, esta falta puede ser vista como una prueba de que "the written word can have had little to do with their survival" ${ }^{12}$.

La dificultad para encontrar "viejas nanas" no excluye que existan casos de supervivencia reconocidos. Un ejemplo de ello es el cantar que se halla en la Comédia Rubena de Gil Vicente:

10 La canción de cuna ha sido reconocida como forma literaria desde hace seis siglos, cuando, en el reinado de Eduardo II, un sacerdote anglo-irlandés escribió: 'Lollai, lollai, pequeño, / ¿por qué lloras con tanta amargura? / Bien tienes que llorar, / desde siempre está prescrito...' Necesariamente existía ya una tradición popular establecida cuando sucedió esto e indudablemente desde mucho antes. Como dijo John de Trevisa en 1398 'las nodrizas usaban nanas y otras canciones para complacer a los niños'. Traduzco de: Iona y Peter OPIE, The Oxford Dictionary of Nursery Rhymes (Oxford: Clarendon Press, 1951), p. 18 [abrev. Opie, Dictionary]. Para el texto de la canción de cuna completo, ver R. T. Davies (ed.), Medieval English Lyrics (London/ Boston: Faber and Faber, 1963), pp. 106-7.

1 Margit FRENK, Corpus de la antigua lírica popular bispánica (siglos XV a XVII) (Madrid: Castalia, 1987), p. xxv [abrev. Frenk, Corpus].

12 .La palabra escrita tuvo poco que ver con su supervivencia. Traduzco de: Opie, Dictionary. p. 8. 
$\mathrm{Ru}, \mathrm{ru}$, menina, ru, ru!, mouram as velhas e fiques tu, coa tranca no cú ${ }^{13}$,

del cual parecen derivar varias versiones que se cantan hoy en día. Las versiones actuales coinciden parcialmente con la antigua, aunque el orden de los elementos ha cambiado, como puede observarse en los cantares ${ }^{14}$.

1a) -O ro ro mi niño ro! co'unha tranquiña no cú morrerán os vellos todos, quedaremos eu e tú ${ }^{15}$.

1b) $\longrightarrow$ mi niño, o co'a tranquiña no cú morrerán os vellos todos quedaremos eu e tú ${ }^{16}$.

Un segundo ejemplo de supervivencia es el del cantar antiguo de tono picaresco, cuyo esquema, ciertos elementos textuales y rima aparecen idénticos en la nana que se canta hoy. Anoto los textos ${ }^{17}$ :

13 Incluido en Frenk, Corpus n. ${ }^{\circ}$ 2048. También ver la sección de suPERvivencias. Otra nana que tiene un antecedente antiguo es "Las vacas de Juana / no quieren comer, / llévalas al agua, / que querrán beber»: Dámaso LEDEsMA, Folklore o cancionero salmantino (Madrid: Imprenta Alemana, 1907) [abrev. Ledesma, Salamanca], y la canción antigua "Las vacas de la virgo / no quieren bever en el río / sino en bacín de oro fino* (Frenk, Corpus, n. ${ }^{\circ} 1151$ ).

14 Margit FRENK, "Supervivencias de la antigua lírica popular" en Estudios sobre lirica antigua (Madrid: Castalia, 1978), pp. 81-112 [abrev. Frenk, Estudios]. El segundo verso aparece también conservado en las adivinanzas antiguas (Frenk, Corpus, n. ${ }^{\circ} 1451$ ) y modernas que designan a la pasa. Es una de las adivinanzas actuales de mayor difusión, tanto en la Península Ibérica como en Latinoamérica, por ejemplo: Una viejecita / muy arrugadita, / y en er c... una tranquita (Rodríguez Marín, Cantos, n. 471 y ver p. 536). Otras fuentes: Aurelio de LLANO ROZA DE AMPUDIA, Esfoyaza de cantares asturianos (Oviedo: Gráficas Summa, 1977), n. ${ }^{\circ} 1209$; y para versiones latinoamericanas: Stanley L. RoBE, Hispanic Riddles from Panama (Berkeley: Univesity of California Press, 1963), n. 305 .

15 Marius SCHNEIDER, "Tipología musical y literaria de la canción de cuna en España", Anuario Musical, 3 (1948), pp. 3-58, n. ${ }^{\circ}$ 5a [abrev. Schneider, Tipologían].

16 Galicia, SchNeIDER, Tipología. n. ${ }^{\circ} 4 \mathrm{~b}$.

17 Uso aquí la terminología de Carlos H. Magis [La lírica popular contemporánea: España, México, Angentina (México: El Colegio de México, 1969), p. 36], para quien "esquema* es "la cristalización en bloque del modo de presentación del material 
Abríme, Menguilla, abríme, y te daré botín cerrado que te rrepique en el pie ${ }^{18}$.

2) Duérmete, niño chiquito, duérmete, que te daré un zapatito calado que te venga justo al pie ${ }^{19}$.

La estructura y elementos comunes en ambos textos son los siguientes: 1) el apóstrofe y la condición, 2) la promesa del regalo, 3) el regalo que es un calzado (en una lectura literal) y 4) el que le quede justo al pie. Las rimas son agudas en -é en los versos pares. Se puede suponer por tanto que el mismo esquema ha sido "rellenado" con la temática propia de la canción de cuna. Otro tipo de supervivencia que se halla en el repertorio estudiado es aquélla donde aparece el estribillo antiguo

$$
\begin{aligned}
& \text { A la dana, dina, } \\
& \text { a la dina dana }{ }^{20}
\end{aligned}
$$

integrado en una versión moderna a la que se le han añadido dos versos, que son los que marcan al texto como canción de cuna ${ }^{21}$ :

$$
\begin{aligned}
& \text { 3) A la dana dina, } \\
& \text { a la dina dana; }
\end{aligned}
$$

poético. El esquema de pensamiento, la solución sintáctica, y la estructura métrica, según los cuales se organiza el contenido, se funden en un molde fijo. Y este molde es el que se estereotipa, ya que el elemento puramente temático queda al margen de la cristalización y el esquema se puede 'rellenar' con diversos contenidos".

18 FRENK, Corpus, n. ${ }^{\circ}$ 1707; Julio CEJADOR Y FRAUCA, La verdadera poesía castellana (Madrid: Tip. de la Revista de Archivos, Bibliotecas y Museos, 1921-1930), 9 vols. Reimpr. Madrid: Arco / Libros, 1987), t. 4, n. 2126 labrev. Cejador y Frauca]. Ver para el significado erótico: Pierre Alzieu, Robert Jammes e Yvan Lissorgues, Floresta de poesias enóticas del Siglo de Oro (Toulouse: France-Ibérie Recherche, 1971), n. ${ }^{\circ} 71$ y Miguel GARCI-GOMEZ, "La abadesa embargada por el pie*, RDTP, XIIV (1989), 7-26.

19 Maximiano TRAPERO, Lírica tradicional canaria (Las Palmas: Viceconsejería de Cultura y Deportes, 1990), p. 61 [abrev. Trapero, Lírica tradicional].

20 Incluido en Frenk, Cotpus, n. 1528 y ver también n. ${ }^{\circ}$ 1287; CEjador y FraUCA, t. 4, n. ${ }^{\circ}$ 2152; Dámaso Alonso y José Manuel BlecuA, Antología de la poesía española (Madrid: Gredos, 1964), n. 434 [abrev. Alonso-Blecua].

21 FRENK, supervivencias de la antigua lírica popular, Estudios, pp. 90-95. También ver las canciones relacionadas con este motivo en TORNER, Lírica, n. 5. 
el niño que llora

se moja la cara ${ }^{22}$.

La gran difusión y los testimonios de la antigua existencia del personaje de las nanas del coco, podrían señalarlas como posible supervivencia. Torner explica que "la costumbre de aterrorizar a los niños con el coco existía ya en España en siglos anteriores" y da como ejemplo la canción que aparece en el Auto de los desposorios de la Virgen (s. XVII) de Juan Caxés ${ }^{23}$ :

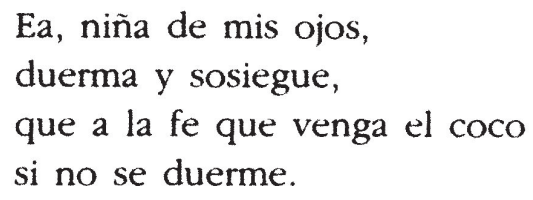

Además, en Covarrubias se halla la definición del coco que «en lenguaje de los niños vale figura que causa espanto y ninguna tanto como las que están a lo escuro y muestran color negro, de Cus, nombre propio de Can, que reinó en la Etiopía, tierra de negros" ${ }^{24}$. A pesar de todos los datos que se conocen no hay elementos suficientes todavía para dar una opinión definitiva.

La versión moderna que goza de mayor popularidad en la Península, que se canta con la melodía de la canción de cuna Wiegenlied de Brahms, tiene su rima en -á:

4a) Duérmete niño duérmente ya, que viene el coco y te comerá ${ }^{25}$.

Otra versión también muy difundida y que comparte la rima con las versiones antiguas es la que se canta en Extremadura:

22 Sixto CóRdova y OÑa, Cancionero popular de la provincia de Santander (Santander: Diputación Provincial, 1980), t. I, p. 377 [abrev. Córdova y Oña].

23 Eduardo M. TORNER, Lírica bispánica: relaciones entre lo popular (Madrid: Castalia, 1966), p. 154 [abrev. Torner, Lírica]. Ver Frenk, Corpus, n. ${ }^{\text {os }} 1815,2183,2198$, donde aparece el personaje del coco. Además, ver el artículo de Fernando ORTIz, -El cocorícamo y otros conceptos teoplásmicos del folklore afrocubano", Archivos del Folklore Cubano, IV, 4 (1929), 289-312.

24 Rodríguez Marín, Cantos, pp. 300 y 515; Torner, Lírica. n. 87.

25 Miguel Manzano Alonso, Cancionero leonés (León: Diputación Provincial, 1990), vol. II, tomo II, p. 201 [abrev. Manzano, León]. 
4b)

Duerme, niño, duerme,

duerme, que viene el coco,

y se lleva a los niños

que duermen poco ${ }^{26}$.

\section{EL RITMO}

Las canciones de cuna, como las canciones de trabajo, "se cantan [...] porque no se tienen facultades para más, se salmodian, se reducen a monótonas canturías" ${ }^{27}$. La melodía y el ritmo, más que en otro género de canciones, son fundamentales, como fue destacado por García Lorca en su conferencia sobre las nanas, donde afirma que la canción de cuna perfecta sería la «repetición de dos notas entre sí, alargando su duración y efectos ${ }^{28}$.

En general, al estudiar las nanas, se pone el énfasis en la importancia de la melodía sobre el texto de la nana, lo cual no parece justificable dado que la selección de sonidos o palabras debe seguir un orden determinado para tener un resultado eficaz. Quizá la estabilidad del repertorio de las nanas que se cantan hoy pueda ser una muestra de ello ${ }^{29}$.

\section{LOS TEMAS DE LAS NANAS}

La difícil tarea de dormir al niño pone a prueba la creatividad (y paciencia) del adulto, quien se sentiría muy limitado si sólo pudiera entonar aquellas nanas que traten cualquiera de los puntos del proceso del sueño del infante. Por ello en el repertorio de cantares de cuna

26 Bonifacio GIL, Cancionero popular de Extremadura (Barcelona: Valls de Cataluña, 1931), p. 154, n. ${ }^{\circ} 10$ [abrev. Gil, Extremadura]. Algunas otras versiones: Asturias, "Duérmete, neñu, - iora!, jora!- / Duérmete, que vien el cocu / A llevar a toos ñeños, / Los ñeños que duermen pocu-; en Puerto Rico, se canta con rima en ú.o: -Duérmase ya el niñito, / Que viene el cuco / Y se lleva a los niños / Que duermen mucho* (Cfr. Rodríguez Marín, Cantos. p. 514).

27 VIDAL, Folclore, p. 45.

28 Federico GARCfa LORCA, "Las nanas infantiles", Obras completas (Madrid: Aguilar, 1966), pp. 91-108, p. 96 [abrev. Lorca, Nanas]. Véase para el ritmo (Schneider, -Tipologia", pp. 4-12).

29 Julia Valenzuela, "Algunas consideraciones en tomo a la canción de cuna., ed. Luis Díaz Viana, Etnología y folklore en Castilla y León (Salamanca: Junta de Castilla y León, 1986), p. 348 [abrev. Valenzuela, :Algunas"]. 
aparecen textos que "no son nanas por su sentido, sino porque siempre, o casi siempre, se cantan para adormir a los niños "30.

De acuerdo con lo anterior podríamos hacer una clasificación entre las nanas propiamente dichas y las nanas funcionales, con lo cual se haría más evidente la necesidad de aclarar la contradicción que puede surgir entre una definición basada en la función únicamente y una definición basada en el texto. En este caso he tenido en cuenta ambos criterios con el fin de conocer cuáles son los cantares que se prefieren. Para mayor claridad he dividido los textos en seis grupos.

En un primer grupo he clasificado a los cantares donde se le ruega al niño que se duerma o que le venga el sueño. Unas veces al niño se le designa como "niño de cuna", "niño de amor", "sol", "lucerito de la mañanan:

5) Duérmete, niño de cuna, duérmete, niño de amor, que a los pies tienes la luna y a la cabecera el sol ${ }^{31}$.

6)

Duérmete, el mi neñu, duérmete, el mi sol, duérmete, pedazos de mi corazón.

$\mathrm{Al}$ roro que te arrullo yo ${ }^{32}$.

7) Ea la nana, ea la nana.

Duérmete, lucerito de la mañana ${ }^{33}$.

\footnotetext{
30 Rodriguez Marí, Cantos, p. 514.

31 Ledesma, Salamanca, p. 105, n. 7 . Véase otra versión en Federico OlmedA, Folklore de Castilla o cancionero popular de Burgos (Sevilla: Librería editorial de María Auxiliadora, 1903. 3. ${ }^{2}$ edición facsímil Burgos: Amabar, 1992), p. 43, n. 13 labrev. Olmeda, Burgos]. Se pueden anotar algunas versiones sefarditas de esta canción: "Dúrmete, mi alma / dúrmete, mi sol / dúrmete, pedazo / de mi corazón •; ‘...] durmite, mi alma, / durmite, mi sol, / porque sos un pedazo / de mi corazón* (ver josé Manuel PEDROSA, "Sobre unas canciones de cuna recogidas de la tradición sefardí de Orienten, Fuentes y correspondencias hispánicas del cancionero sefardi de Oriente: catorce estudios comparativas (Tesis doctoral, Madrid: UNED, 1993), 366-91, p. 367 labrev. Pedrosa, ,Fuentes"].

32 Eduardo M. TORNER, Cancionero musical de la lírica popular asturiana (Madrid: Torner, 1920, 2. ${ }^{a}$ ed. facsímil Oviedo: Instituto de Estudios Asturianos, 1986), n. ${ }^{\circ} 140$ labrev. Torner, Asturias. Compárese con: Vidal, Folclore, p. 49; Gil, Extremadura, p. 154.

33 La Mancha, SCHNEIDER, -Tipología-, n. ${ }^{\circ} 23 a$.
} 
Curiosamente, en estas nanas, quizás las más dulces, el niño aparece relacionado con elementos celestiales. También dentro de este grupo incluyo:

8) Arroró, niño chiquito, arrorró, rorró, rorró; con el arroró y el sueño ya mi niño se durmió ${ }^{34}$.

9) A la nana, nana, duérmete, chiquetito, y hasta mañana leeré ${ }^{35}$.

10) Este niño guapo que nació de día quiere que lo lleven a la romería.

Dorme os nenos tamén dormes tú ${ }^{36}$.

En algunas ocasiones el niño no sólo tiene el papel protagonista, sino que aparece como personaje con voz propia: nanita y duerme.

-En la cunita, madre, quiero mecerme ${ }^{37}$.

En contraste con las nanas anteriores existe todo un subgrupo de cantarcillos donde se hace explícito el insomnio del pequeño. El problema puede ser visto con dulzura como en los ejemplos 14, 15 y 16; otras veces

4- VIDAL, Folclore, p. 47, n. ${ }^{\circ} 1$.

35 TORner, Asturias, n. 426.

36 Galicia, SCHNeIDER, "Tipología", n. ${ }^{\circ}$ 2d. PEDrosa ("Fuentes", pp. 366 y ss.), explica que el mismo texto ha sido adaptado al sistema de referencias de las comunidades sefardies del Oriente, donde se substituye el término cristiano 'romería' por 'confetería'. Uno de los ejemplos es: "Este chico nenu / que nació de día, / quere que lo lleven / a la confetería.

3. Rodríguez Marin, Cantos, n. ${ }^{\circ}$ 16. Ver también Vidal, Folclore, p. 68, n. ${ }^{\circ}$; otros ejemplos: "Son son, vine vine / Son son, vine vine / Si la son venía, jo m'adormiría, / si la son em ve, jo m'adormiré. Joan Amades, Folklore de Catalunya: Cançoner (Barcelona: Selecta, 1951; 3. ${ }^{2}$ edición, 1982, p. 3, n. ${ }^{\circ} 11$ ); "Mese, mese, mese, / tetita no mereses; / yo que me mesí, / tetita meresí. (Rodríguez Marí, Cantos, p. 847). 
se pide ayuda celestial, en el texto $17 \mathrm{o}$, finalmente, con desgana y desesperación en el cantar 18:

\begin{tabular}{|c|c|}
\hline 14) & $\begin{array}{l}\text { Este menino } \\
\text { quer dormir: } \\
\text { mas o soninho } \\
\text { não quer vir }{ }^{38} \text {. }\end{array}$ \\
\hline 15) & $\begin{array}{l}\text { El mi niño tiene sueño } \\
\text { y no se quiere dormir, } \\
\text { y el picarito sueño } \\
\text { ya no quiere venir }{ }^{39} \text {. }\end{array}$ \\
\hline 16) & $\begin{array}{l}\text { A la nana nanita, } \\
\text { mi niña duerme } \\
\text { con el ojito abierto } \\
\text { como la liebre }{ }^{00} \text {. }\end{array}$ \\
\hline 17) & $\begin{array}{l}\text { ¡Ró, ró, ró! } \\
\text { E o seu soño não quer vir: } \\
\text { Os Anjinhos do Céu venham } \\
\text { Ajúda-lo a dormir }{ }^{41}\end{array}$ \\
\hline 18) & $\begin{array}{l}\text { Duérmete meu meniño } \\
\text { si non queres calar chora } \\
\text { ¡ora! meniño jora! }{ }^{42} \text {. }\end{array}$ \\
\hline
\end{tabular}

El segundo grupo está compuesto por las nanas donde aparecen aquellos personajes misteriosos y amenazantes cuyo poder reside "precisamente [en] su desdibujo". El más famoso es el "coco", pero existen en todas partes y sus nombres varían de región en región: 'En el Sur, el 'toro' y la 'reina mora' son las amenazas; en Castilla, la 'loba' y la 'gitana', y en el Norte de Burgos se hace una maravillosa sustitución del 'coco' por la 'aurora' ${ }^{43}$. En las canciones estudiadas sólo se hallan dos de las criaturas: el coco (ver p. 7) o papão y la mora. Unas veces el locutor puede usar un tono amenazante, otras un tono protector:

38 LeITE dE VASCONCELLOS, “Canções", n. ${ }^{\circ} 124$.

39 Salamanca, José Manuel Pedrosa, .Fuentes", p. 373 y ahí mismo ver la nota para bibliografia de otras versiones.

40 Madrid, SCHNEIDER, "Tipología", n. ${ }^{\circ} 10 \mathrm{~g}$.

41 Leite de Vasconcellos, "Canções", n. 35.

42 Galicia, SCHNEIDER, *Tipología*, n. $15 f$.

43 LORCA, Nanas, p. 98. 
19) Duérmete, niño chiquito,

antes que venga la mora porque anda de casa en casa por saber qué niño que llora ${ }^{44}$.

20) O Papão, vae-te embora, tira-te d'aí: menino bonito não é para ti ${ }^{45}$.

El tercer apartado lo forman aquellas nanas que se refieren al trabajo de la casa o las labores de los padres. Algunas veces la madre o la nodriza pide al niño que se calle, pues debe hacer los trabajos del hogar:
Calla, niño, calla, que tengo que hacer, lavar los pañales, ponerme a coser al rum rum del alma rum rum ${ }^{46}$.

En otras coplas parecen conjugarse el cansancio y la desesperación, y la nana se vuelve un ruego para liberarse del cuidado del niño:

22) San António, leve António, S. António me leve a mim! Os Anjos do Céu me levem Este menino para si! ${ }^{47}$.

23) Este niño que teño no colo chamare Xan Benitiño e Antonio

\footnotetext{
+4 Entre otras versiones de esta conocida nana ver Manzano, Cancionero leonés, n. ${ }^{\text {*s }} 965$ y 967; Andalucía, SCHNEIDER, "Tipologían, n. ${ }^{\circ}$ 19a.

45 Leite de VASCONCEllos, :Canções", n. ${ }^{\circ} 127$; y ver Torner, Lírica, n. 87.

* Olmeda, Burgos, p. 44, n. ${ }^{\circ} 16$; LeITE de Vasconcellos, "Canções", n. ${ }^{\circ}$ 79. Es interesante anotar que existe una canción de cuna inglesa de voz masculina donde es el padre quien cuida al niño mientras la madre fue al molino: .Hush thee, my babby, / Lie still with thy daddy, / Thy mammy has gonne to the mill, / To grind thee some wheat / To make thee some meat, / Oh, my dear babby, lie still. ['Duérmete, mi niño, / quédate con papá, / tu mamá ha ido al molino / para moler un poco de trigo / para hacerte la comida, / Oh, mi querido niño, quédate']. Traduzco de: OPIE, Dictionary, p. 58 .

47 LeTte de Vasconcellos, :Canções", n. ${ }^{\circ} 169$.
} 
Dios que mo deu que m'o crie logo

e que me quite este entrenque do colo ${ }^{48}$.

En otras ocasiones se prefiere recordar al niño su desamparo debido a la ausencia de sus padres. A veces se le dice que volverá la madre para alimentarlo, otras se le deja la duda. Por ejemplo:

24) Cala, menino, cala, que a maisinha logo vem, foi lavá los coeirinhos á fontinha de Belém ${ }^{49}$.

25)

O, ó menino, ó, teu pai foi ó eiró, tua mãi àborboleta, logo te vem a dar a teta ${ }^{50}$.

La crueldad del mensaje puede llegar al extremo de recalcar la orfandad y por ende el absoluto desamparo del niño. Las causas pueden ser la muerte o el abandono:

26) Cala, cala, meu menino, Quem é que te há-de arrolar? Tua mãi foi para o moinho, Teu pai caíu ao mar $^{51}$.

27) Este niño chiquito no tiene madre; lo parió una gitana lo echó en la calle ${ }^{52}$.

El objetivo principal de las canciones de cuna es dormir al niño. Una vez que el infante ha conciliado el sueño, escuchamos aquellos cantares donde el locutor pide a los diversos seres naturales o supranaturales que no perturben el sueño del pequeño. Estos forman el cuarto apartado:

\footnotetext{
48 Galicia, SCHNEIDER, "Tipología", n. ${ }^{\circ} 1 \mathrm{a}$.

49 LEITE DE VASCONCELLOS, "Canções", n. 56.

50 Firmino A. MARTINS, Folklore do concelbo de Vinbais, [I] (Coimbra: Universidade, 1928), p. 255.

51 LeTte dE VASCONCEllos, “Canções*, n. 78.

52 Florentino Castro Guisasola, Canciones y juegos de los niños de Almería (Almería: Editorial Cajal, 1985), p. 53, n. 7.
} 
28) Pajarito que cantas

en la laguna,

no despiertes al niño

que está en la cuna ${ }^{53}$.

29) O, ó, ó,

Moça do telhado,

Deixa-me o menino

Dormir sossegado ${ }^{54}$.

30) - Meu neno garrido

quen dormi in dor

non o dispertes alchírincholi.

En o cantaie e o lalaire

en o si chora o arrulaire ${ }^{55}$.

31) O' Papào, vae-te embora

De cima d'esse telhado,

Deixa dormir o menino

O seu sono descansado ${ }^{56}$.

En el quinto apartado he agrupado aquellas canciones donde el niño deja de tener el papel protagonista y se vuelve mera excusa para comunicar otros sentimientos de la mujer. Un grupo importante lo forman las muy difundidas "nanas de la adúltera":

32) -Fue el mio Xuán a Uvieu, dió i el aire en culu mira que llueu vieno.

Ahora non meu neñu, non ahora non ${ }^{5}$.

33) Si el padre del niño no hubiera venido, t'abriera la puerta durmieras conmigo.

‘3 Andalucía, Rodríguez MARIN, Cantos, p. 847. Ver también las interpretaciones dadas por Schneider en "Tipología", pp. 14-18.

if Leite de VAsconcellos, “Cançòes", n. ${ }^{\circ} 120$.

55 Galicia, SCHNEIDER, "Tipología", n. ${ }^{\circ} 14 \mathrm{a}$.

s6 LeITE de VAsConcellos, "Canções", n. ${ }^{\circ}$ 89; Torner, Lírica. n. ${ }^{\circ} 87$.

‘7 TORner, Asturias, n. 372 . Ver Ledesma, Salamanca, p. 105, n..$^{\circ}$; Luis Diaz Viana y. Miguel manzano Alonso, Cancionero popular de Castilla y León (Salamanca: Centro de Cultura Tradicional y Diputación Provincial, 1989), t. 1, p. 13, n. ${ }^{\circ} 1$ labrev. Díaz Viana-Manzanol. 


\author{
Alororo \\ que te arrullo yo ${ }^{38}$. \\ 34) Maldita sea el alma \\ del que no me entiende \\ está su padre en casa \\ del niño que duerme, \\ y al ronrón ${ }^{49}$.
}

Asimismo incluyo en este apartado el cantar cuyo tópico es la "malmaridada". Como en las anteriores coplas, donde la mujer es la protagonista:
Quando era solteirinha,
Usava fitas e laços:
Agora, que seu casada,
Trago o meu filho nos braços ${ }^{60}$.

El grupo antes analizado podría ser considerado como el de aquellas canciones donde predomina el punto de vista femenino, es decir, donde la mujer toma la palabra para expresar sus deseos y angustias: una canción femenina ${ }^{61}$.

58 Kurt SCHIndler, Folk Music and Poetry of Spain and Portugal (New York: Hispanic Institute, 1941) [abrev. Schindler, Folk] n. 362.

59 Díaz Viana-MANZANO, p. 13, n." 1. Otra versión: "Quien pica a la puerta, /que venga a otra hora, / que está el padre en casa / del niño que llora. // Angora no, / angora no, mi niño, / angora no. // Demonio del cura, / iqué mal me entendiste!: / ique está el padre en casa / del niño que hiciste! // Angora no, / angora no, mi niño, / angora no" (MANZANo, León, n. ${ }^{\circ}$ 975a). Un cantar muy sugerente sobre la mujer adúltera se canta en Estados Unidos: "There's a man comes to our house every single day, / Papa goes to work and the man comes to stay. / Papa does the work, and mama gets the pay, / And the man comes to our house every single day" en Bess LomaxHowEs, "Folksongs and Function: Some Thoughts on the American Lullaby", Journal of American Folklore, 87 (1974), pp. 140-48. La antigüedad de las "nanas de la adúltera" parece remontarse, según Julio CAMARENA LAUCIRICA, Cuentos tradicionales de León (Madrid: Diputación Provincial de León, 1991), p. 271, al Decamerón de Bocaccio (London: Chatto \& Windus, 1924), VII: 1. También ver Eduardo MarTinez TORNER, Cancionero musical de la lírica popular asturiana (Oviedo: Instituto de Estudios Asturianos, 1976), n. ${ }^{\circ} 267$.

60 LeITE dE VASCONCEllos, “Canções", n. ${ }^{\circ} 15$.

61 Aquí uso el término canción femenina en el sentido dado por Margit Frenk, cfr. "La canción popular femenina en el Siglo de Oro", ed. Alan Deyermond \& Ralph Penny, Actas del I Congreso Anglo-Hispano, II: Literatura (Madrid: Castalia, en prensa), quien 
En el sexto apartado he incluido lo que se puede denominar "nanas funcionales , es decir, textos cuyo tema no son los de un cantar de cuna. En este grupo existen dos categorías. En la primera están los villancicos que funcionan como cantar de cuna y en la segunda aquellas canciones cuyo tema es variado. En el primer grupo se encuentran las conocidas -nanas de la manzana", como han sido denominadas por Pedrosa ${ }^{62}$ :

Señora Santa Ana, ¿por qué llora el niño? Por una manzana que se le ha perdido ${ }^{63}$.

O José, embala, o menino co'a mão, nanja co'o pé: qu'esse menino qu'embalas e Jesus de Nazaré ${ }^{64}$.

38) La Virgen está lavando $y$ en un romero tendiendo, los angelitos cantando y el agua clara corriendo ${ }^{65}$.

afirma que "las canciones de mujer son aquellas en que el yo poético, la voz que habla, es claramente de mujer, mientras que en las canciones que llamo femeninas a esa característica viene a sumarse otra más importante: la expresión de puntos de vista que se nos revelan como específicamente femeninosn.

${ }_{62}$ Otro ejemplo de este tipo de canciones es la de eel piojo y la pulga / se quieren casar" (ver Rodríguez Marín, Cantos. pp. 511-512). El uso de villancicos como nanas (o viceversa) parece tener una larga tradición, así lo demuestra el cantar de Gil Vicente que aparece en el Auto da Sibila Casandra (ed. de Th. R. Hart, "Clásicos Castellanos", 156. Madrid: Espasa-Calpe, 1968, copla 655): «Ro, ro, ro, / nuestro Dios y Redemptor, / no lloréis, que dais dolor / a la Virgen que os parión (Frenk, Corpus, n. ${ }^{\circ} 1322$ ).

${ }^{63}$ Rodríguez Marín, Cantos, n. ${ }^{\circ}$ 6501. Este es un villancico muy difundido; anoto algunas otras fuentes: SCHINDLER, Folk. n. ${ }^{\circ} 137$ y 599; VIDAL, Folclore, n. ${ }^{\circ} 55 \mathrm{a}$, donde se encontrarán comentarios. Para el origen del villancico ver el trabajo de Arcadio de LARREA PALACÍn, Villancicos y canciones de Nocbebuena (Tetuán: Editorial Cremades, 1955), y para otras versiones de la unana de la manzana ver la misma obra, p. 166. Para el papel de Santa Ana en la literatura tradicional medieval ver Francesca SAUTMAN, "Saint Anne in Folk Tradition. Late Medieval France, ed. Kathleen Ashley y Pamela Sheingor, Interpreting Cultural Symbols. Saint Anne in Late Medieval Society (Athens, London: The University of Georgia Press, 1990), pp. 69-94.

of LeITE de VASConcellos, "Cançòes", n. ${ }^{\circ} 29 \mathrm{a}$.

${ }^{65}$ VIDAl, Folclore. n. ${ }^{\circ} 55 a$. Este cantar está muy difundido tanto en España como en Latinoamérica. Ver LarRea Palacín, Villancicos, pp. 113, 116, 118, 119, 131, 134, 180. 
La gran frecuencia con la que aparecen los cantares a lo divino, usados como nana, suscita la cuestión de cuáles son los elementos que favorecieron tal relación o cómo se estableció. En opinión de Pérez Vidal, en las nanas «se debe haber producido un doble movimiento lírico: el de cantos de cuna vueltos a lo divino y el de villancicos navideños empleados luego como cantos de cuna». Podría añadirse que habría que tomar en cuenta la similitud de la estructura entre las oraciones y las nanas y la semejanza de las funciones que cumplen ambas ${ }^{66}$.

En la segunda categoría incluyo aquellas canciones cuyo tema puede ser variado; generalmente aparecen coplas amorosas, pero que se utilizan como canciones de cuna:

39) - Por aquella calle a la larga hay un gavilán perdio que dicen que va a llevarse la paloma de su nio ${ }^{67}$.

40) Só á meia-noite durmo um soninho descansado, quando os fillos 'stão dormindo e o marido está deitado ${ }^{\text {kt. }}$.

41) Co este vento do mar, vento mareiro, non sayas a pescar meu mariñeiro. Co este vento do mar non sayas a pescar; non sayas, non, meu ben,

66 VIDAL, Folclore, p. 38. En Italia, según LeITE dE VASCONCELlos (-Canções", p. 788): -Ném só em cànticos profanos se expande a musa da Itália [...] usam-se pelo Natal representaçōes drámaticas em que se figura a Virgem Maria a entoar cançōes ao Menino-Jesus: ninne-nanne del santo Natale. Otro fenómeno de adaptación que se podría citar aquí es el de una canción que utiliza el mismo esquema de una copla de boda: 42) .Luisiño é unha rosa / Luisimo é un clavel / Luisiño é un espelló / sua nai mirase n'ál. /lara lara la la la. La copla que pertenece a la canción de boda es: "La madrina es una rosa / y el padrino es un clavel / y la novia es un espejo / el novio se mira en él. (TORNER, Lírica, n. ${ }^{\circ}$ 6, p. 31); también ver J. G. Cummins, The Spanish Traditional Lyric (Oxford: Pergamon Press, 1977), p. 122, n. 215.

67 LORCA, Nanas, p. 99. Para ver la tipología formulística de este cantar ver José Manuel PEDROSA, .La canción de ronda Las calles del amor entre los sefardíes de Oriente, Revista de Folklore, 134 (1992), pp. 39-47.

68 LeITE dE VAsconcellos, "canções", n. ${ }^{\circ} 81$. 
co este vento que ven

non tornarás acá ${ }^{69}$.

\section{LAS VOCES DE LA NANA}

De las canciones analizadas, sesenta $(89,6 \%)$ son monólogos, cuarenta y tres $(64,2 \%)$ de ellas con apóstrofe y diecisiete $(25,4 \%)$ sin; cinco $(7,5 \%)$ se pueden considerar como narrativas y dos $(2,99 \%)$ diálogos. Existe una variedad de personajes a los cuales se dirige el locutor. En la mayoría de los casos, la voz se dirige al niño utilizando expresiones como niño, $m i$ niño, meu menino, menino, nino chiquito, mi niña, chiquetito, meu ruliño. En otras canciones el locutor se dirige a personajes como el pajarito o a la 'moça' que amenazan con perturbar el sueño del niño; también la voz espanta al papão para que deje en paz al niño. Asimismo aparecen el marinero o una invocación al popular San Antonio o San Benitiño ${ }^{70}$.

De acuerdo con el estudio de las voces, en las canciones de cuna se encuentran catorce textos $(20,9 \%)$ en los que habla una voz femenina. En la variante es el tópico de la malmaridada el que sirve como marca para identificar la voz:

El problema para determinar la voz aparece cuando nos hallamos con las frases "mi niño" o cualquiera de sus variantes. A primera vista parece obvio aceptar estas expresiones como propias de la voz de la mujer; sin embargo, se encuentran textos como los siguientes:

43) Duérmete, niñito mío, que tu madre no está en casa. que se la llevó la Virgen de compañera a su casa ${ }^{72}$.

69 Rodriguez Marín, Cantos, p. 849.

70 Es interesante anotar que tanto figura San Antonio en las nanas, que cualquier copla referente al santo se ha empleado para dormir a los niños* (VIDAL, Folclore, p. 71).

7 Gil, Extremadura, p. 154. Inicio del romance .La mujer engañada. (Romancero general de León, ed. Diego Catalán y Mariano del Campo, II, Madrid: Seminario Menéndez Pidal, Universidad Complutense, Diputación Provincial de León, 1991), n. 56.

72 Badajoz, Rodriguez Marín, Cantos, p. 847. 
44) Ora, meu meniño, ora, quem vos a de dá la teta, se tu pai vai no moliño e tua nai na leña seca ${ }^{73}$.

En los dos ejemplos anteriores "mi niño" o "meu meniño" se han convertido en clichés. De ahí que sea imposible usarlos como única marca para determinar el género de la voz. De acuerdo con esto se hallaron cuarenta y seis $(68,7 \%)$ cantares con voz indeterminada. No aparecen, en la tradición hispánica, cantares con voz masculina. Por otra parte, aparecen cinco canciones narrativas $(7,5 \%)$ y dos dialogadas $\left(2,99 \%\right.$, ver $\left.n .{ }^{\circ} 35\right)$. Un ejemplo de las primeras es el siguiente villancico:

$$
\begin{aligned}
& \text { A fontinha era d'ouro } \\
& \text { e a àgua de cheiro; } \\
& \text { e o menino era filho } \\
& \text { d'um Deus verdadeiro }{ }^{74} \text {. }
\end{aligned}
$$

En resumen, la mayoría de las nanas no poseen una marca explícita que las identifique como de voz femenina. Sin embargo, la ausencia de la voz masculina, la temática con referencias predominantemente femeninas como las labores domésticas ( $n .{ }^{\circ} 21$ ), sus deseos de amor ( $n .{ }^{\circ} 33$ ) y sus quejas ( $\left.\mathrm{n}^{\circ} 42\right)$, son elementos que las sitúan dentro del dominio de la canción de mujer.

\section{CONCLUSIONES}

La antigüedad de las nanas como género ha sido aceptada por los estudiosos. Sin embargo, hasta el siglo XVII no se registran los vocablos

73 Galicia, Rodríguez Marín, Cantos, p. 848. Esta nana y su versión de Burgos (•Echate, niño al ron ron, / que tu padre está al carbón / y tu madre a la manteca / no te puede dar la tetan) muestran antigüedad — según García Lorca- pues ambas melodías están escritas en un tetracordo, dentro del cual desenvuelven su esquema. Por la simplicidad y su puro diseño son canciones que no tienen par en ningún cancionerom (Nanas. p. 103).

74 Leite DE VAsconcellos, "Canções", n. ${ }^{\circ} 13$. Los elementos distintivos de la voz del texto pueden ser explícitos o implícitos. Considero marcas explícitas a todos aquellos elementos gramaticales (pronombres, sustantivos, adjetivos, verboides) cuyo género esté determinado. Este tipo de marcas se pueden dividir en: 1) aquellas que identifican el locutor, quien habla; 2) al alocutario, a quien se habla y 3) al delocutor, de quien se habla. Las marcas implícitas son aquellos tópicos o símbolos que, a través del contexto, identifican la voz de la canción. Ver Mariana MASERA, La voz femenina en la antigua lírica hispánica* (Tesis licenciatura, México: UNAM, 1991). 
que pasan a designar hoy las canciones de cuna, tanto en la Península Ibérica como en Italia e Inglaterra.

El hecho de que hoy el repertorio de las nanas esté compuesto por una mayoría de cantares de los que no se han encontrado trazas más allá del siglo XIX, no excluye la posibilidad de que su transmisión se haya producido de forma latente en el dominio oral durante un largo período, como muestran las supervivencias encontradas en los cantares estudiados.

El mundo de las nanas es complejo; abarca desde los cantares llenos de ternura hasta los argumentos más crueles. Parece que hay nanas de todos los tonos: unas veces se ruega, otras se intimida, otras sirven de oración protectora. En conclusión y pese a la especificidad de la función de las nanas, existen dentro de ellas registros con gran variedad de posibilidades.

En el caso de los cantares que se utilizan como nanas se ha visto una gran preferencia por el uso de villancicos, cuya íntima relación con las canciones de cuna aún no ha sido totalmente estudiada. Así, también existen aquellos cantares de temas varios donde aún quedaría por estudiar cuáles son las razones para la preferencia de un texto. ¿Es mayormente el tema o la melodía lo que determina la opción del locutor? ${ }^{76}$.

En el aspecto de la voz en el nivel del enunciado un 20,89\% de los cantares tienen marca femenina, un $70 \%$ carecen de marcas que identifiquen el género de la voz, y no hay canciones de voz masculina. Existe también una pequeña proporción, en torno al $9 \%$, de canciones narrativas y dialogadas. La ausencia de la voz masculina y la preferencia por temas y tópicos femeninos son rasgos que podrían señalar a la mayor parte de las nanas como canciones de mujer, sin que ello implique que deban ser exclusivamente canciones donde se expresen punto de vista femeninos ${ }^{\pi}$.

\section{MARIANA MASERA \\ Department of Hispanic Studies Queen Mary and Westfield College University of London}

75 Valenzuela, "Algunas", p. 354.

76 Ver para funciones de las nanas en el artículo de Julia Valenzuela ya citado.

" Compárese Luisa del GiudicE, -Ninna-nanna-Nonsense? Fears, Dreams, and Falling in Italian Lullaby", Oral Tradition, 3 (1988), 270-293. Agradezco el apoyo y consejo recibidos del Prof. Alan Deyermond para la realización de este artículo, así como la generosidad con sus materiales de José Manuel Pedrosa. 
El papel tradicional de la mujer como encargada del cuidado del niño quizás ha sido una de las principales causas de que las canciones de cuna sean identificadas como canciones de voz femenina y en la mayoría de los casos se ha dejado a un lado el análisis de los textos mismos. Este último aspecto es el que me propongo analizar aquí.

Lullabies have been considered by most scholars as chansons de femme. Generally, this is not based on the persona who speaks in the text, but on the fact that women are in charge of the trasmission of the songs because of their traditional role. The aim of this article is precisely the study of lullabies from the point of view of the speaker. 